\title{
Aneurysmal benign fibrous histiocytoma of the anal canal: a rare differential diagnosis
}

\author{
Raj Amarnani ${ }^{1,2}$ (D) Athur Harikrishnan ${ }^{3}$
}

Accepted: 22 November 2019 / Published online: 16 December 2019

(C) The Author(s) 2019

\begin{abstract}
Background To our knowledge, we report the first case of an aneurysmal benign fibrous histiocytoma occurring in the anal canal. Methods Clinical, histological, radiological and surgical data pertaining to this patient were analysed. Additionally, a literature review on aneurysmal benign fibrous histiocytoma was conducted.

Results We describe a 48-year-old Caucasian male presenting with a 2-week history of a painful anus, fresh rectal bleeding and tenesmus. Digital rectal examination identified a tender firm mass in the anal verge. Magnetic resonance imaging revealed high signal in the anal canal. Flexible sigmoidoscopy revealed an ulcerated 3-cm indurated lesion at the four o'clock position. Biopsies taken of the mass confirmed the diagnosis of an aneurysmal benign fibrous histiocytoma (BFH). Following a discussion in the colorectal multi-disciplinary team, the patient was counselled for an excision of the lesion. Diathermy dissection was performed to completely excise the tumour with a margin involving the fibres of the anal sphincter. The patient made a full recovery and had no residual symptoms. Histology of the excised specimen confirmed clear margins of the BFH.

Conclusions This paper aims to highlight a rare differential diagnosis for an anal mass. An aneurysmal BFH most often presents as a painless mass within the dermis and subcutaneous tissue. As such, this case presents a diagnostic challenge to both colorectal surgeon and histopathologist due to its low incidence and unusual location. We further present the clinical and radiographic evidence to confirm the diagnosis. Additionally, we discuss the literature pertaining to this condition and its optimal management.
\end{abstract}

Keywords Aneurysmal benign fibrous histiocytoma $\cdot$ Anal canal $\cdot$ Colorectal surgery

\section{Introduction}

Aneurysmal benign fibrous histiocytoma (BFH) of the skin is an exceedingly rare tumour, accounting for $0.3 \%$ of all softtissue neoplasms and $1.7 \%$ of all BFHs [1]. However, the tumour is classified as being of intermediate malignant potential and is therefore a diagnosis that is of clinical significance despite its rarity [2]. To our knowledge, we report the first case of aneurysmal BFH occurring in the anal canal in a gentleman presenting with a painful anal lesion.

Raj Amarnani

raj1@doctors.net.uk

1 University College London Hospitals NHS Foundation Trust, London, UK

2 Nuffield Department of Orthopaedics, Rheumatology and Musculoskeletal Sciences, University of Oxford, Oxford, London, UK

3 Sheffield Teaching Hospitals NHS Foundation Trust, Sheffield, UK

\section{Case report}

A 48-year-old Caucasian male presented with a 2-week history of a progressively enlarging hard painful anal lesion associated with two episodes of fresh rectal bleeding. The bleeding was present only on the toilet paper and not mixed in with the stool. This was also associated with a 2-week history of tenesmus. He experienced no other change in the bowel habit or weight loss. His past medical history included haemorrhoids, gout, depression and Freiberg's disease (for which he has had a right total hip replacement). He has had no previous abdominal or colorectal surgery. He has a twenty pack-year smoking history and he drinks approximately ten units of alcohol per week. He has no relevant family history of note and is not on any regular medication. Digital rectal examination revealed a firm ulcerated lesion at the four o'clock position, present at the anal verge and inside the anal canal.

T2-weighted magnetic resonance imaging (MRI) of the lesion showed an unusual high signal in the anal canal (Figs. 1, 2, and 3). Flexible sigmoidoscopy revealed an 


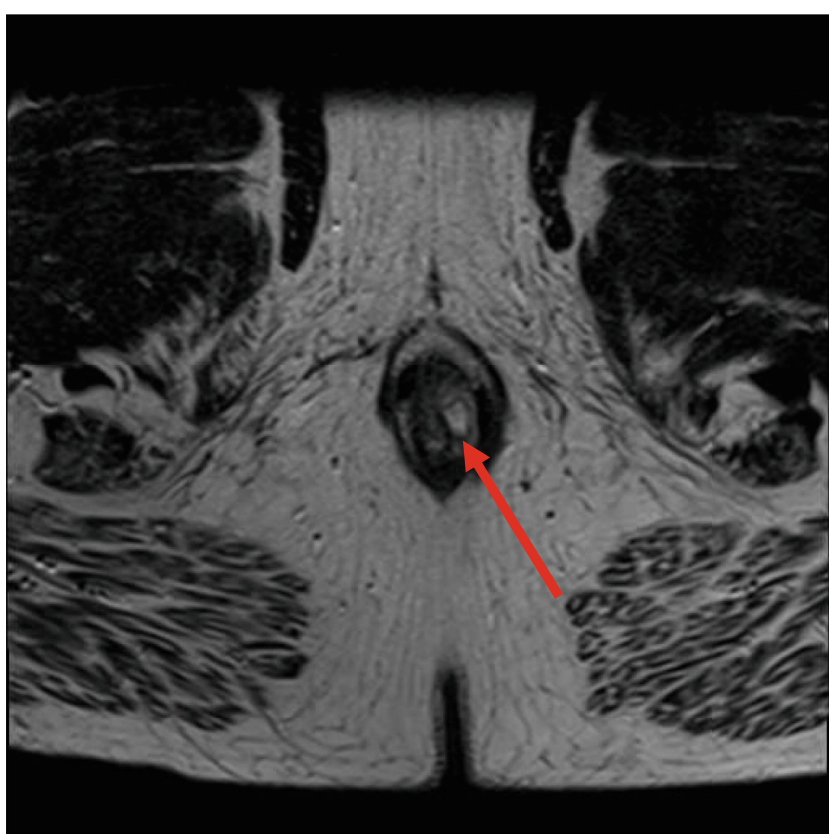

Fig. 1 T2-weighted axial magnetic resonance imaging of the patient, demonstrating an unusually high signal in the anal canal

ulcerated 3-cm indurated lesion at the four o'clock position. The lesion had a central 1-cm ulcer with rolled edges. Punch biopsies of this lesion were inconclusive. His case was discussed extensively at a multi-disciplinary team meeting after which it was decided that a further examination under anaesthesia would be undertaken with deeper biopsies. These further deeper biopsies confirmed a diagnosis of an aneurysmal benign fibrous histiocytoma.

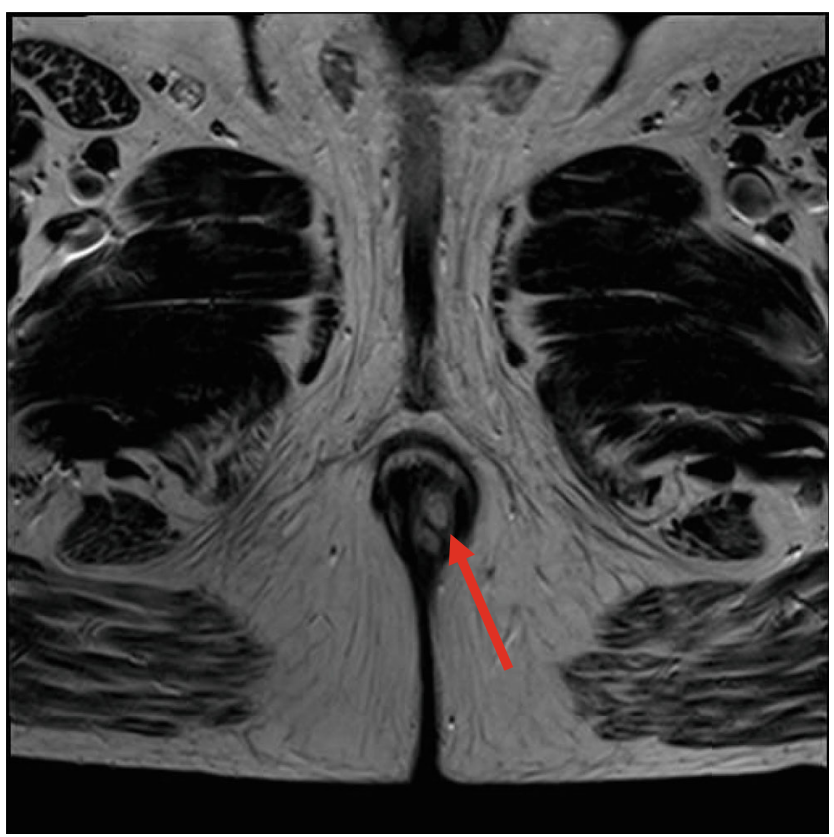

Fig. 2 T2-weighted transverse magnetic resonance imaging of the patient, demonstrating an unusually high signal in the anal canal

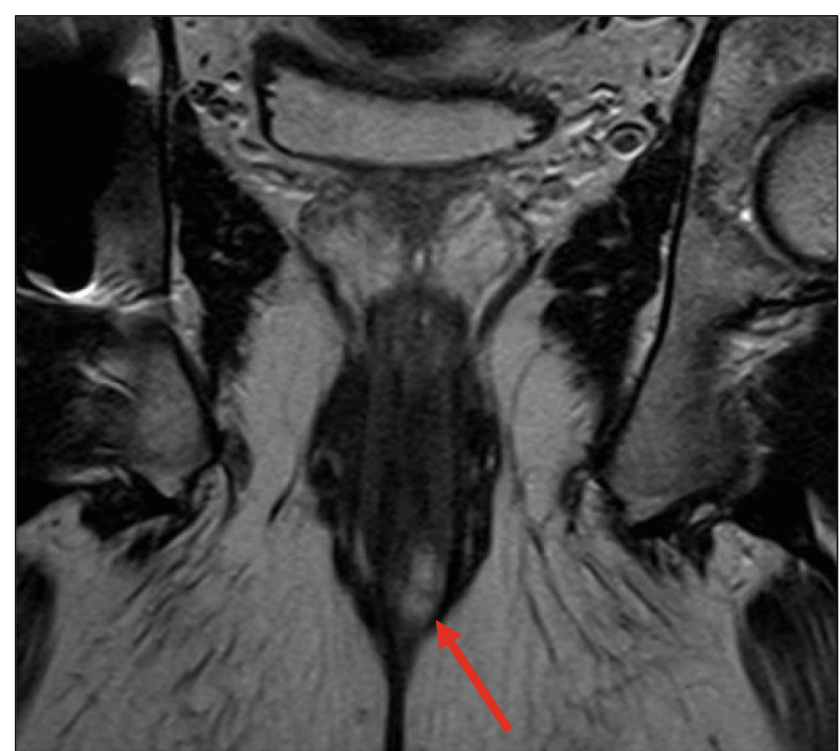

Fig. 3 T2-weighted coronal magnetic resonance imaging of the patient, demonstrating an unusually high signal in the anal canal

The patient subsequently underwent surgery for the lesion under spinal anaesthetic. A diathermy dissection was performed to completely excise the tumour with a margin that involved the fibres of the anal sphincter. His post-operative management included a 5-day course of metronidazole, regular tramadol, lactulose and a 4-week follow-up in the outpatient department. The anal wound healed satisfactorily within 6 weeks and the patient suffered no residual symptoms 2 months after the surgery.

\section{Discussion}

BFH is a superficial dermal subcutaneous lesion, involving spindle-shaped cells resembling fibroblasts and myofibroblasts alongside oval cells resembling histiocytes [3]. Numerous subtypes of BFH exist, including cellular, atypical, aneurysmal, epithelioid and atrophic.

The aneurysmal variant of BFH was initially described by Santa Cruz et al. [3]. The disease most often affects young adults and children and is extremely rare, accounting for approximately $0.3 \%$ of all soft-tissue neoplasms [2]. Aneurysmal $\mathrm{BFH}$ has the potential to grow very large and histologically, it is characterised by large, blood-filled tissue spaces lined by histiocytes $[2,3]$. Most commonly, the tumour arises in the extremities or sites with normal lymphoid tissue such as the axilla, inguinal and supraclavicular regions and the antecubital fossa. However, there have been reported cases of aneurysmal BFH occurring in the head and neck, trunk and lower limbs [4-7]. Furthermore, we found one clinical report [8] of a common polypoid BFH presenting in the anal canal, not an aneurysmal $\mathrm{BFH}$. 
Aneurysmal BFH most often presents as a painless mass within the dermis and subcutaneous tissue [9]. Some patients may experience concurrent non-specific symptoms such as pyrexia and malaise, which may suggest cytokine production by the tumour. Curiously, our patient presented with an isolated painful mass in the anal canal. Clinically, an aneurysmal $\mathrm{BFH}$ often can present variably and can mimic fibrous tumour and other benign or malignant vascular tumours. As such, a histopathological diagnosis is mandatory for diagnosis. Additionally, the aneurysmal variant is often larger than an ordinary BFH and usually undergoes faster growth due to intralesional haemorrhage and pigmentation.

Whilst accepted management of aneurysmal BFH is by a complete excision, it has been suggested that there is up to a $23 \%$ recurrence rate [7]. Furthermore, aneurysmal BFH has been classified to as being of intermediate malignant potential [7]. As such, although an aneurysmal BFH may not appear on the working differential diagnosis of a colorectal surgeon, it is an important consideration that can provide diagnostic challenges to both clinician and histopathologist alike.

\section{Conclusion}

Aneurysmal BFH is a rare finding, but should be considered as possible diagnosis in the context of an anal mass. Diagnosis is challenging as it can imitate numerous other conditions and has varied, non-specific clinical symptoms and radiological findings. Complete surgical excision is the current recommended management of this condition and on-going followup is advisable to monitor for re-occurrence. To our knowledge, we present the first reported case of an aneurysmal benign fibrous histiocytoma occurring in the anal canal. The patient was successfully treated with complete diathermy dissection and has had no residual symptoms since.

\section{Compliance with ethical standards}

Conflict of interest The authors declare that they have no conflict of interest.

Informed consent Informed consent was obtained from all individual participants included in the study.

Open Access This article is licensed under a Creative Commons Attribution 4.0 International License, which permits use, sharing, adaptation, distribution and reproduction in any medium or format, as long as you give appropriate credit to the original author(s) and the source, provide a link to the Creative Commons licence, and indicate if changes were made. The images or other third party material in this article are included in the article's Creative Commons licence, unless indicated otherwise in a credit line to the material. If material is not included in the article's Creative Commons licence and your intended use is not permitted by statutory regulation or exceeds the permitted use, you will need to obtain permission directly from the copyright holder. To view a copy of this licence, visit http://creativecommons.org/licenses/by/4.0/.

\section{References}

1. Matushansky I, Charytonowicz E, Mills J, Siddiqi S, Hricik T, Cordon-Cardo C. MFH classification: differentiating undifferentiated pleomorphic sarcoma in the 21st Century. Expert Rev Anticancer Ther [Internet]. 2009 Aug;9(8):1135-44. Available from: http:// www.ncbi.nlm.nih.gov/pubmed/19671033

2. Calonje E. Soft-tissue tumours and tumour-like conditions Rook's Textbook of Dermatology, 8th ed. Burns T, Breathnach S, Cox N, Griffiths C, editors. 2010. pp. 56.16-20

3. Santa Cruz DJ, Kyriakos M. Aneurysmal ("angiomatoid") fibrous histiocytoma of the skin. Cancer [Internet]. 1981 Apr 15;47(8): 2053-61. Available from: http://www.ncbi.nlm.nih.gov/pubmed/ 6261935

4. Albonico G, Pellegrino G, Maisano M, Africa G, Pedriali M, Nenci I. [Aneurysmatic fibrous histiocytoma: case report and reivew of the literature]. Pathologica [Internet]. 2001 Apr;93(2):136-8. Available from: http://www.ncbi.nlm.nih.gov/pubmed/11428292

5. Calonje E, Fletcher CD. Aneurysmal benign fibrous histiocytoma: clinicopathological analysis of 40 cases of a tumour frequently misdiagnosed as a vascular neoplasm. Histopathology [Internet]. 1995 Apr;26(4):323-31. Available from: http://www.ncbi.nlm.nih. gov/pubmed/7607620

6. Persson PB, Persson AB. Fatigue. Acta Physiol [Internet]. 2016 Jul; Available from: https://doi.wiley.com/10.1111/apha.12756

7. Das A, Das A, Bandyopadhyay D, Mishra V, Saha A. Aneurysmal benign fibrous histiocytoma presenting as a giant acrochordon on thigh. Indian Dermatol online J [Internet]. 6(6):436-8. Available from: http://www.ncbi.nlm.nih.gov/pubmed/26753147

8. AbdullGaffar B, Abdulrahim M, Ghazi E. Benign fibrous histiocytoma presenting as anal canal polyp: first case report. Ann Diagn Pathol [Internet]. 2013 Oct;17(5):464-5. Available from: http://www.ncbi.nlm.nih.gov/pubmed/22999485

9. Antonescu CR, Dal Cin P, Nafa K, Teot LA, Surti U, Fletcher CD, et al. EWSR1-CREB1 is the predominant gene fusion in angiomatoid fibrous histiocytoma. Genes Chromosomes Cancer [Internet]. 2007 Dec;46(12):1051-60. Available from: http://www. ncbi.nlm.nih.gov/pubmed/17724745

Publisher's note Springer Nature remains neutral with regard to jurisdictional claims in published maps and institutional affiliations. 